\title{
A Review on Influence of Growth Regulator and Culture Condition on Micro-Propagation of Ginger (zingiber officinale)
}

\author{
Tajebe Mosie \\ Horticulture department, Holeta Agricultural Research Center, P.O. Box 31, Ethiopia
}

\begin{abstract}
How to cite this paper: Mosie T. (2019) A Review on Influence of Growth Regulator and Culture Condition on Micro-Propagation of Ginger (zingiber officinale). International Journal of Food Science and Agriculture, 3(3), 200-204.
\end{abstract}

DOI: $10.26855 /$ ijfsa.2019.09.009

*Corresponding author: Tajebe Mosie, Horticulture department, Holeta Agricultural Research Center, P.O. Box 31, Ethiopia.

Email: tajebemu@gmail.com

\begin{abstract}
Ginger is used in different medicinal systems of the world for a wide range of disorders. Commercially it is available in various forms, such as green ginger (fresh ginger), dry ginger, ginger powder, ginger oil, ginger oleoresin and preserved ginger. Now a day there is an outbreak of ginger wilt disease throughout the world which pushes researchers and experts to work on specifically; the application of plant tissue culture technique to produce disease free plant has been practiced. Thus the objective of the study is to review the influence of growth regulator and culture condition on micro propagation of ginger.Culture medium without growth regulator fails to stimulate the shoot bud initiation in the explants after four weeks of culture. Depending up on the type and concentration of growth regulators; number of days required for bud break varies from 6-10. Among the growth regulators, the medium containing BA (2.0-4.0 mgl) induced bud sprout in about 6-7 days. Auxin promotes the growth of intact roots and excised root sections but only at a relatively lower concentration range. If its concentration is high, it will suppress morphogenesis in cultured plants. The interaction of cytokinins and explant type had also significant differences for both leaf number and shoot length. The interaction of BAP and NAA produced high number of shoots (in the range of 1419 shoots per explants) although BAP alone produced 12-13 shoots and 9 roots per explants. The influences of different growth regulators at different concentrations have important roles in promoting well developed roots. The $\mathrm{pH}$ condition of the medium should be adjusted to 5.8 before autoclaving at 1.04 $\mathrm{kg} / \mathrm{cm}^{2}$ pressure and $121^{\circ} \mathrm{C}$ temperature for $15-20$ minute. All cultures should be incubated in $16 \mathrm{~h} \mathrm{light} / 8 \mathrm{~h}$ dark photoperiod (cool, white fluorescent light $\left.-30 \mu \mathrm{mol} \mathrm{m}^{-2} \mathrm{~S}^{-1}\right)$ for successful production of plants.
\end{abstract}

\section{Keywords}

Culture medium, Ginger, In vitro propagation, Rhizome

\section{Introduction}

Ginger (Zingiber officinale Roscoe) is belongs to the family Zingiberaceae. It is a perennial plant that is usually grown as an annual crop and harvesting as a spice. Ginger is native to South East Asia, now which is grown commercially in most tropical regions [1]. It is an important tropical horticultural crop, valued throughout the countries as an important spice for its nutritional as well as medicinal properties. Ginger is propagated with underground rhizomes vegetatively and cultivated in many countries including India, China, Japan, Indonesia, Australia, Nigeria and West Indies [2].

Ginger is used throughout the world as a spice and fresh herb for cooking and other value added products [3]. It has immense usage in many of the different medicinal systems of the world for a wide variety of disorders. In traditional medicines ginger is used to treat nausea, diarrhea, motion sickness, migraine, dyspepsia, heart problems, arthritis, and 
to reduce flatulence and colic. Moreover, it is believed to treat the common cold, flu-like symptoms, headaches, and painful menstrual periods. Ginger is known to be effective as an appetizer and improvesthe digestive system [4]. It is an important tropical herbaceous perennial plant, with the rhizome valued for its extraction of oleoresins and essential oils, as well as direct useful for culinary purposes is increasing worldwide [5]. Ginger is available in various forms commercially; these are green ginger, dry ginger, ginger powder, ginger oil, ginger oleoresin and preserved ginger [6].

\section{According to [7] ginger production is constrained by:}

1. Ginger is propagated by rhizome with a low proliferation rate, and the rhizome is also the economically used part, which limits the availability of ginger seeds,

2. It is easily infected by soil-borne pathogens (bacterial wilt, soft rot and nematodes) which causes heavy loss in yield,

3. Rhizomes show degeneration under long-term vegetative propagation

4. Breeding is difficult due to poor flowering and seed set. Therefore in vitro propagation is a true-to-type multiplication technique, which provides uniform plants with genetic identity [8].

The problem with ginger cultivation is high infestation by pest and disease such as, Phyllosticta leaf spot, storage rots and bacterial wilt or rhizome rot that caused by soil born bacteria Ralstonia (Pseudomonas) Solana cearum [9]. The application of plant tissue culture technique to produce disease free plant has been practiced for many crops. Several studies had successfully demonstrated for the application of tissue culture technique in ginger [10]. Therefore thisreviewarticle may be appropriate guidance for the assessment of the influence of growth regulator and culture condition onmicro propagation of ginger.

\subsection{Tissue Culture Techniques}

According to [11] Plant tissue culture is an essential component of plant biotechnology in which the promising plant produced may be cloned in cultures under aseptic conditions. Tissue Culture is mainly used for

- Obtaining disease free plants.

- Rapid propagation of plants those are difficult to propagate.

- Somatic hybridization.

- Genetics improvement of commercial plants.

- Three main techniques generally used in tissue culture are - Micro propagation through the enhanced multiplication of axillary bud.

- Organogenesis.

- Somatic embryogenesis.

Plant in vitro technology can have three major areas, namely micro propagation, somatic cell genetics and generation of transgenic plant [11].

\subsubsection{In Vitro Micro Propagation}

The protocol developed by [12] can be used for rapid multiplication and large scale production of disease-free planting material on artificial media under controlled environment. Factors that can improve rhizome size, while reducing production costs need to be identified before micro propagated plants can be recommended for routine use in the ginger industry as a source of 'clean' planting material. Integration of this protocol with field techniques for seed rhizome production can be summarized into the following steps:

In vitro micro propagation of ginger is highly influenced by culture medium formulation and condition. Culture medium can be prepared by agar for solidification, sucrose and growth regulators and $\mathrm{pH}$, light condition and temperature should be adjusted for successful propagation. 


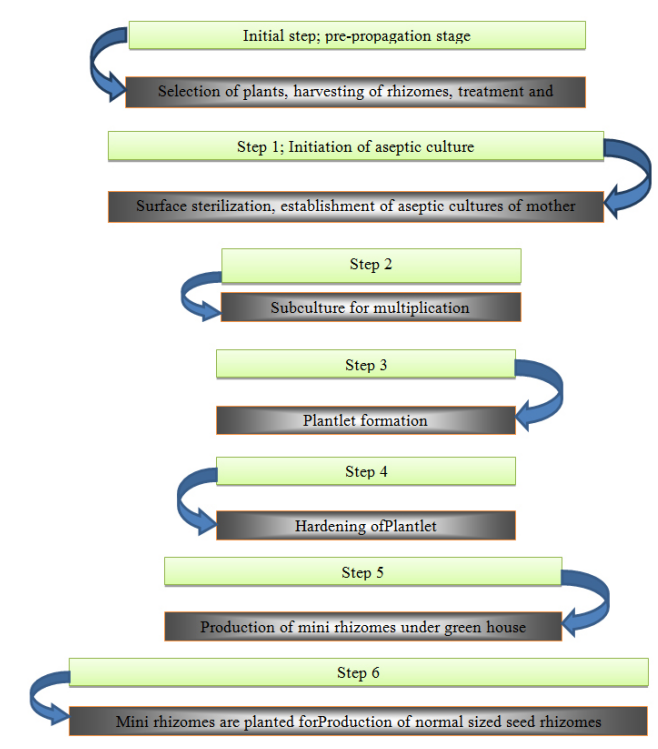

Figure1. Ginger micro propagation protocol integrated with field technique for seed rhizome production.

\subsection{Effect of Growth Regulator}

Culture medium without growth regulator fails to stimulate the shoot bud initiation in the explants after four weeks of culture [13]. Depending up on the type and concentration of growth regulators; number of days required for bud break variesfrom 6-10. In culture medium devoid of growth regulators, the time required for bud sprout is more than 20 days [14].

Among the growth regulators, the medium containing BA (2.0-4.0 mgl) induced bud sprout in about 6-7 days. Kinetin was ineffective in stimulating bud sprout as compared to BA [14]. There is an endogenous auxin to promote ginger rooting but it is not sufficient [13]. Small number of root appears in culturing on auxin-free basal medium and at lower level of NAA treatments. According to [10], auxin promotes the growth of intact roots and excised root sections but only at a relatively lower concentration range. If its concentration is high, it will suppress morphogenesis in cultured plants [15].The interaction of cytokinins and explants type had also showed significant differences for both leaf number and shoot length [16].The interaction of BAP and NAA produced high number of shoots (in the range of 14-19 shoots per explants) although BAP alone produced 12-13 shoots and 9 roots per explants.

\subsection{Culture Medium and Condition}

Sterilized blotted explants must be implanted on to the [17] agar-gelled medium fortified with various concentrations and combinations of growth hormones and culture condition. The influences of different growth regulators at different concentrations have important roles in promoting well developed roots. The $\mathrm{pH}$ of the medium should be adjusted to 5.8 before autoclaving at $1.04 \mathrm{~kg} / \mathrm{cm} 2$ pressure and $121^{\circ} \mathrm{C}$ temperature for $15-20$ minute. All cultures should be incubated in $16 \mathrm{~h}$ light $/ 8 \mathrm{~h}$ dark photoperiod (cool, white fluorescent light $-30 \mu \mathrm{mol} \mathrm{m}-2 \mathrm{~S}-1$ ). The cultures must be incubated at $25 \pm 3{ }^{\circ} \mathrm{C}$ in diffused light under $60-70 \%$ relative humidity in the culture room. The cultures are maintained by regular subcultures at 4 week intervals on fresh medium with the same medium compositions [13].

\subsection{Callus Induction upon Interaction of Growth Regulators and Culture Condition}

The presence of 2, 4-dichlorophenoxyacetic acid (2, 4-D) at 1.5-5.0 mgl-1 in the culture medium resulted in callus growth for ginger explants [18]. The rate of regeneration increased when growth regulators are completely removed from the culture medium in subsequent subcultures. However, these growth regulators are required to initiate organogenesis and plantlet formation [18].

\subsubsection{Sub Culturing}

Micro shoots formed in the test tubes are taken out 5-6 weeks after inoculation. The shoots are separated by dissecting 
them in the sterile environment of laminar air flow cabinet with sterile dissecting needle and forceps. Then dissected shoots are placed in the test tubes containing fresh media. Shoot multiplication efficiency can betasted for a period of 32 months (33 subcultures). Single plantlets separated from multiple shoot cultures can be sub cultured and the shoot multiplication rate persisted [18].

\subsubsection{Acclimatization}

One of the major obstacles in the application of tissue culture methods for plant propagation has been the difficulty in successful transfer of plantlets from the laboratory to the field [19]. The reasons for such a difficulty appear to be related to the dramatic change in the environmental conditions. The environment of the culture vessel is one of low light intensity, with very high humidity $(100 \% \mathrm{RH})$ and poor root growth, while the greenhouse and/or field conditions are typified by very high light intensity, low humidity and micro flora [20]. This acclimatization difficulty comes from both growth regulators applied to culture medium which is responsible for root and shoot growth and culture conditions. These reasons for such a difficulty appear to be related to the dramatic change in the environmental conditions.

- Main procedures of acclimatization can be summarized as:

- Remove plantlets with well-developed roots from the medium

- Wash thoroughly under running tap water to remove adhering solid medium [21].

- Transplant plantlets to plastic pots containing sterilized sand and clay at ratio of 1:4.

- Maintain plantlets in a semi shaded net house with $80 \% \mathrm{RH}$ at $28 \pm 2{ }^{\circ} \mathrm{C}$ for hardening [21].

- Hydroponics culture can be performed by placing plantlets in perlite under which hydroponic solution is circulated.

The hydroponic solution consisted of tap water supplemented with micro and macro organic/inorganic elements. Stock solution recipe can be prepared and applied based on the method of [22].

\section{Conclusion}

The main problem in ginger cultivation is high infestation by pest and disease such as, Phyllosticta leaf spot, storage rots and bacterial wilt or rhizome rot that caused by soil born bacteria. Therefore currently ginger producers tend to biotechnological tools to produce pest and disease free planting material for high quality and yield production of ginger. Different plant parts, such as rhizome buds, shoot tips, leaf bases, and inflorescence parts can be selected as potential explants of micro propagation. Prior to placement on culture media, explantsmust be pre-treated repeatedly with distilled water and bleach (detergents).Proper interaction between growth regulators, explant type and appropriate $\mathrm{pH}$, light and temperature conditions must meet for successful propagation and acclimatization of new plantlets to external environments for production of disease free ginger seed.

\section{Reference}

[1] Abeykera WKSM, Illeperuma CK, Amunugoda PNRL and Wijeralasm SW. Composition of Ginger (Zingiberofficinale Rosccoe) Clones Dried at Different Temperatures for Oil and Oleoresin Content. Sri Lankan journal of Agricultural sciences. 2005;42:34-42.

[2] Ravindran PN and NirmalBabu K. Ginger the Genus Zingiber. United States of America. 2005.

[3] Bartley J and Jacobs A. Effects of drying on flavor compounds in Australian-grown ginger (Zingiberofficinale). J. Sci. Food Agric. 2000; 80(2): 209-215.

[4] Wresdiyati T, Astawaa M, Muchtadi D and Nardiana Y. Antioxidant Activity of Ginger (Zingiberofficinale Rosccoe) Oleoresin on the Profile of Superoxide Permutase in theKidney of Rats under Stress Condition. Journal Technologi Dan Industri Pangan, 2007; 8(2): 118-122.

[5] Food and Agriculture Organization of the United Nations (FAO). Country notes for the FAOSTAT domain on production and prices, www.Faostat.org.2008.

[6] Kizhakkayi J and Sasikumar B. Variability for quality traits in a global germplasm collection of ginger (Zingiberofficinale Rosccoe) current trends in biotechnology ginger and pharmacy. 2009; 3(3): 254-259. 
[7] Guan Z, Guo YH, Sui XL, Li W and Zhang X. Photosynthetica, 2008; 46 (2): 193-201.

[8] Das A, Kesari V and Rangan L. Plant regeneration in Curcuma species and assessment of genetic stability of regenerated plants. Biol. Plant, 2010; 54:423-429.

[9] NirmalBabu K, Samsudeen K, Minoo D, Geetha SPand Ravindran PN. Tissue culture andbiotechnology of Ginger. In: Ravindran, P. N. and NirmalBabu, K. (Eds.). Ginger the Genus Zingiber. 2005.

[10] Abdelmageed AHA, Faridah QZ, Norhana FMA, Julia AA and Midhzar AK. Micropropagation of Etlingeraelatior (Zingiberaceae) by using axillary bud explants. Journal of Medicinal Plants Research. 2011; 5:4465-4469.

[11] Sharma GK, Jagetiya S and Dashora R. General Techniques of Plant Tissue Culture. 2015.

[12] upta RK and Verma VS. Micropropagation and hardeningin horticultural crops: Low cost options a case study of Ginger (Zingiberofficinale). In: Proceedings of 11th International Conferenceon Plasticulture and Precision Farming, New Delhi. 2005; 153-56.

[13] Kambaska KB and Santilata S. Effect of Plant Growth Regulator on Micropropagtion of Ginger (Zingiberofficinale Rosc.) cv- Suprava and Suruchi. Journal of Agricultural Technology, 2009;5(2): 271-280.

[14] Edison S, Ramana KV, Sasikumar B, NirmalBabu K andSanthosh JE. Biotechnology of Spices, Medicinal \& Aromatic Plants. Indian Society for Spices, Calicut, Kerala, India. 1997.

[15] Smith RH. Plant Tissue Culture Techniques and Experiments. United States of America: Academic Press. 2013.

[16] Biruk Ayenew, Wondyifraw Tefera and Bekele Kassahun. In vitro propagation of Ethiopian ginger (Zingiberofficinale Rosc.) cultivars: Evaluation of explant typesand hormone combinations. African Journal of Biotechnology. 2012; 11(16): 3911-3918.

[17] Murashigae T and Skoog F. A revised medium for rapid growth and bioassays with tobacco tissue cultures. Physiologia Plantarum, 1962; 15:473-497.

[18] Ma X and Gang DR. Phytochemistry, 2006; 67: 2239-2255.

[19] Wardle K, Dobbs KB and Short KC. In-vitro acclimatization of aseptically cultured plantlets to humidity. Journal of American Society of Horticultural Science, 1983; 108: 386-389.

[20] Desjardins YA, Goselin and Yellow S. Acclimatization of In vitro straw berry plantlets in Co2 enriched environment and supplementary lighting. Journal of American Society of Horticultural Science, 1987; 112: 846-852.

[21] Das A, Kesari V and Rangan L. Micropropagation and cytogenetic assessment of Zingiberspecies of Northeast India. Biotech, 2012;3:471-479.

[22] Resh H, Barbara S. Hydroponic Food Production. 1989. 